\title{
Prolonged QTc Dispersion Correlates with Coronary Artery Disease in Acute ST Elevated Myocardial Infarction (STEMI)
}

\author{
N I Sharafat, ${ }^{1} \mathrm{M}$ Khalequzzaman, ${ }^{2} \mathrm{M}$ Akhtaruzzaman, ${ }^{3}$ A K Choudhury, ${ }^{4}$ S Hasem, ${ }^{5}$ TA Choudhury, ${ }^{6}$ \\ A.B.M Nurun Nobi, ${ }^{7}$ Shikder MR, ${ }^{8}$ M Shaheen Kabir, ${ }^{9}$ A K Akanda ${ }^{10}$ \\ Dept. of Cardiology, NICVD, Dhaka.
}

Keywords:

$Q T_{c}$ dispersion, STEMI,

Coronary artery

disease.

\begin{abstract}
:
Background: It has been found that there is strong association of QT dispersion and QT dispersion ratio with extent and severity of coronary artery disease. Qualitative importance of QTc dispersion on the base line ECG in patients with MI is recognized clinically but quantification of this phenomenon is less commonly used in clinical practice, which might be a better independent risk predictor of this group of patients.

Methods: A total of 100 patients were selected, Study populations sub-divided into two groups on the basis of QTc dispersion. In group I(comparison group): QTc dispersion is $<60$ milliseconds (msec) in group II (study group): QTc dispersion e"60milliseconds(msec). 50 patients in each group. QT dispersion was calculated on standard resting 12 lead ECGs. QT interval was measured from the beginning of the inscription of the QRS complex to the point at which the T wave returned to the isoelectric line. Angiographic severity of coronary artery disease was assessed by-Vessel score, Friesinger score and Leaman score. Interpretation of coronary angiogram was reviewed by at least two cardiologists. .

Results: The mean vessel score for group I patients was $1.16 \pm 0.68$ and that of group II patients was $2.30 \pm 0.64$ and the mean difference was statistically significant $(p<0.05)$. Patients those had single vessel involvement had mean QTc dispersion 57.05, patients those had double vessel disease mean QTc dispersion was 102.00 and patients those had triple vessel involvement had mean QTc dispersion 177.60. There was a strong positive correlation with the QTc dispersion and increasing number of vessel involvement (Pearson's correlation coefficient). The mean Friesinger score for group I patients was $4.84 \pm 2.56$ and that of group II patients was 9.80 2.60 . The mean difference was significantly $(p<0.05)$ higher in group II patients. There was a strong positive correlation between the QTc dispersion and Leaman score (Pearson's correlation coefficient). In group I patients $56 \%$ had insignificant coronary artery disease and $44 \%$ had significant coronary artery disease defined by Friesinger index $(n=100)$. In group II patients $6 \%$ had Insignificant coronary artery disease \& had 94\% significant coronary artery disease.

Conclusion: QTc dispersion $>60 \mathrm{~ms}$ had independent predictive value for the severity of coronary artery disease. The greater the QTc dispersion the higher the number of coronary artery involvement. We observed that there is a positive correlation between prolonged $Q T$ dispersion and coronary artery disease severity in terms of Vessel score, Friesinger score, Leaman score.
\end{abstract}

(Cardiovasc. j. 2013; 5(2): 173-181)

Introduction:

Coronary heart disease (CHD) is a major cause of mortality globally and this health problem is reaching pandemic in both developed, as well as in developing countries. ${ }^{1}$ Ischaemic heart disease was the leading cause of death in developed country and second leading cause of death in developing country and by the year 2020, ischaemic heart disease will hold first place in the World Health Organization's list of leading cause of disability. ${ }^{2}$ The South Asian countries of India, Pakistan, Bangladesh, Srilanka and Nepal contribute the highest proportion of the burden of Cardiovascular Diseases (CVDs) compared to any other region globally. ${ }^{3-6}$ Estimates from the global burden of Disease study suggests that by the year 2020 this part of the world will have more individuals with atherosclerotic Cardiovascular disease than any other region. ${ }^{7}$ Bangladesh is a small country with vast population. Cardiovascular disease becoming a significant burden on health care services in Bangladesh. ${ }^{8}$ Khandaker et al found that Myocardial infarction is one of the leading cause of death in Bangladesh mostly in the $4^{\text {th }}$ decade of life. In a study of 2690 patients, in

Address of Correspondence: Dr. Sharafat Nurul Islam, Department of Cardiology, National Institute of Cardiovascular Diseases, Dhaka, Bangladesh. 
hospital mortality was $11.8 \%$. The main cause of death in MI was pump failure and ventricular fibrillation. ${ }^{9}$ According to one survey, prevalence rate of ischaemic heart disease in Bangladesh was $3.4 \%$ in $2001 .{ }^{10}$ Today the utility of the ECG has been over shadowed by the ability of the echocardiography and intervention cardiology to evaluate the possible site of lesion of coronary artery after myocardial infarction. ${ }^{11}$ Determination of the QT interval dispersion by means of a standard ECG at rest has been widely used for cardiovascular risk assessment during the last 15 years as one of the recent explanations for the development of life threatening ventricular arrhythmias is based on the prolongation and dispersion of repolarization between neighboring regions of myocardium. ${ }^{12}$ There is considerable evidence that QT dispersion may indirectly reflect underlying nonhomogenecity of ventricular repolarization. ${ }^{13} \mathrm{An}$ increase in QT dispersion is reported to predict the occurrence of life-threatening ventricular tachyarrhythmias and sudden cardiac death in patients with ischemic heart disease. ${ }^{14}$ Tikiz, et al. had studied the patients with single vessel CAD had wider resting QT dispersion when compared to control group, which further increased significantly with exercise. ${ }^{15}$ Stierle, et al. shows a relation Between QT dispersion and the Extent of Myocardial Ischemia in Patients with three vessel Coronary Artery disease. In patients with coronary artery disease, QT dispersion increased from a baseline value of $39 \pm 7 \mathrm{msec}$ to a peak ischemic stress value of $63 \pm 10$ msec. Patients with normal coronary arteries showed almost unchanged values of QT dispersion (41 \pm 9 vs $42 \pm 7 \mathrm{~ms}$ ). ${ }^{16}$ Yilmaz, et al. found the association of QT dispersion and QT dispersion ratio with extent and severity of coronary artery disease. In their study the more extent and severe CAD was related to higher QT Dispersion. ${ }^{17}$ Yunus, et al. shows QT interval dispersion decreases after successful coronary artery revascularization and increases with restenosis. Therefore, QT interval dispersion may be a marker of recurrent ischemia due to restenosis after PTCA. ${ }^{18}$ Polychronis A, et al. shows QT dispersion and QTc dispersion are significantly increased during spontaneous angina in patients with documented CAD and history of previous myocardial infarction. QT dispersion and QTc dispersion were significantly higher during the anginal episode compared to the painless conditions. ${ }^{19}$ The inter-lead variation of QT interval provides an index of the heterogeneity of ventricular repolarization. The most commonly used index to calculate QT dispersion has been the of difference between the longest and shortest QT intervals on the twelve-lead electrocardiography (ECG), which is often adjusted for heart rate. ${ }^{15}$ Qualitative importance of QTc dispersion on the base line ECG in patients with MI is recognized clinically but quantification of this phenomenon is less commonly used in clinical practice, which might be a better independent risk predictor of this group of patients. QTc dispersion may be of use as a simple, accurate and inexpensive complementary tool for risk stratification in patients with acute ST elevation myocardial infarction.

Objective of the study was to find out the association of the severity of coronary artery disease in acute STelevation myocardial infarction (STEMI) with QTc dispersion.

\section{Materials and Methods:}

This is Cross sectional study done in the department of Cardiology, National Institute of Cardiovascular Diseases (NICVD), Dhaka from May 2011 to December 2011. Considering inclusion and exclusion criteria, A total of 100 patients were selected, Study populations subdivided into two groups on the basis of QTc dispersion.Patients of first acute ST elevation myocardial infarction (STEMI) underwent CAG in NICVD during the same hospital stay. 50 patients with QTc dispersion is $<60$ milliseconds (msec) was included in group I (comparison group) and 50 patients with QTc dispersion is e"60 milliseconds (msec) was included in group II (study group).

Patients with paced rhythm, old myocardial infarction, arial fibrillation, bundle -branch blocks, interventricular conduction defects, AV block, sinus node dysfunction. Wolff - Parkinson - White Syndrome, patients taking medications could affect QT interval such as - quinidine, amiodarone and digitalis etc, post CABG status/ Post PCI status, cardiomyopathy, serious co- 
morbid conditions like cerebrovascular disease or renal impairment (serum creatinine ${ }^{3} 2.0 \mathrm{mg}$ dl), congenital heart diseases(cong. Long QT syndrome) and valvular heart disease were excluded.

Measurement of QTc dispersion: QT dispersion was calculated on standard resting 12 lead ECGs obtained at the time of admission at a paper speed of $25 \mathrm{~mm} / \mathrm{sec}$ and with a calibration of $1 \mathrm{mv}$, where at least 9 leads show measurable QT interval. ECG is manually measured with hand help calipers. QT interval was measured from the beginning of the inscription of the QRS complex to the point at which the $\mathrm{T}$ wave returned to the isoelectric line (Return to the TP base line). For calculation of QT dispersion, 3 consecutive cycles were measured in each lead and the mean of these 3 cycles was taken as mean QT interval of that lead. If a $\mathrm{U}$ wave is present, termination of the $\mathrm{T}$ wave was defined as the nadir of the curve between the $\mathrm{T}$ and $\mathrm{U}$ waves. Leads where the $\mathrm{T}$ wave ends or $\mathrm{T}$ wave morphology could not be clearly observed was excluded from analysis. The PR segment was taken as the baseline to solve the difficulty in identifying the end of the $\mathrm{T}$ wave in the presence of ST depression. QT dispersion (QTd) was calculate as the difference between the longest (QT max) and the shortest QT (QT min) interval recorded. The $Q T$ interval was corrected by using Bazett's formula ( $\mathrm{QTc}=\mathrm{QT} /$ square root of $\mathrm{R}-\mathrm{R}$ interval in seconds). Corrected QT dispersion (QTcd) was defined as the difference between the maximum and minimum QTc for a given heart rate. So $\mathrm{QTcd}=\mathrm{QTc}$ maximum- QTc minimum. The normal mean QTcd is $45 \pm 15 \mathrm{~ms} .{ }^{20}$

All patients admitted in Cardiology department of NICVD, Dhaka, fulfilling the inclusion criteria and exclusion criteria was considered for study. Informed written consent was taken from each subject before enrollment. Acute STEMI was diagnosed by ESC/ACC guideline 2004. Meticulous history and detailed clinical examination were carried out and recorded in data collection sheet. Demographic data, such as, age, sex, occupation, BMI $(\mathrm{kg} / \mathrm{m} 2)$ were noted. Following risk factor profile were asked and scrutinized: Smoking, Hypertension, Diabetes, Dyslipidemia and Family history of
CAD. Pulse, BP and other vital parameters were recorded. QTc dispersion was calculated for all patients at the time of admission from admission ECG. Baseline laboratory investigation CK(MB), lipid profile, Random Blood Sugar, \& Echocardiographic ejection fraction was recorded. Coronary angiography was performed in the patients during hospital stay. Angiographic severity of coronary artery disease was assessed by- Vessel score, Friesinger score and Leaman score. An interpretation of coronary angiogram was reviewed by at least two cardiologists. All the information was properly noted in the preformed data sheet. All the data entry and analysis was done by using SPSS (statistical package for social science) software program.

\section{Results:}

Demographic profile of both groups were shown in the tables (I, II,) and fig(1) which revealed there was no significant difference in term of age, sex and occupation.

\section{Table-I}

Age distribution of the study patients $(n=100)$

\begin{tabular}{|c|c|c|c|c|c|}
\hline \multirow{2}{*}{$\begin{array}{l}\text { Age in } \\
\text { years }\end{array}$} & \multicolumn{2}{|c|}{ Group I $(\mathrm{n}=50)$} & \multicolumn{2}{|c|}{ Group II $(\mathrm{n}=50)$} & \multirow[t]{2}{*}{$\mathrm{P}$ value } \\
\hline & Number & $\%$ & Number & $\%$ & \\
\hline$\leq 40$ & 12 & 24.0 & 6 & 12.0 & \\
\hline $41-50$ & 13 & 26.0 & 14 & 28.0 & \\
\hline $51-60$ & 19 & 38.0 & 26 & 52.0 & \\
\hline$>60$ & 6 & 12.0 & 4 & 8.0 & \\
\hline Mean_SD & $49.3 \pm 9.9$ & $52.2 \pm 9.5$ & $0.13^{\mathrm{ns}}$ & & \\
\hline Range & $(25-67)$ & $(25-79)$ & & & \\
\hline$(\min -\max$ & & & & & \\
\hline
\end{tabular}

$\mathrm{ns}=$ Not significant. $\mathrm{P}$ value reached from unpaired t-test

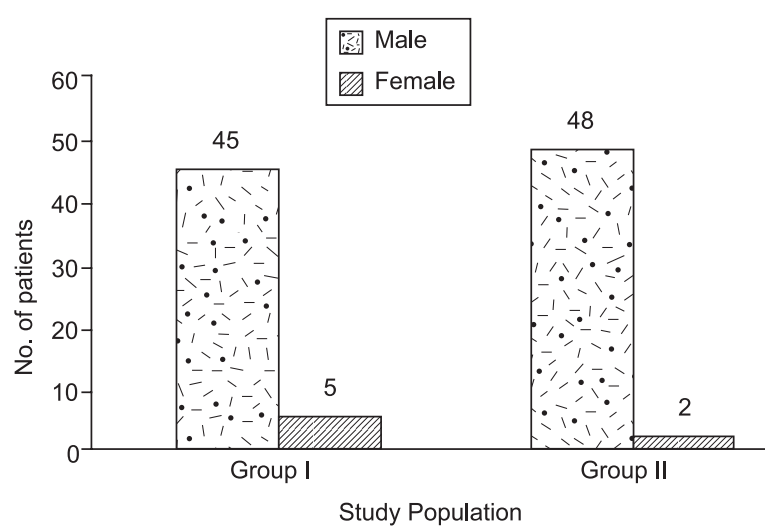

Fig.-1: Sex distribution among the study patients $(n=100)$ 
Table-II

Distribution of the study patients according to occupation $(n=100)$

\begin{tabular}{lccccccc}
\hline Occupation & \multicolumn{2}{c}{$\begin{array}{c}\text { Group I } \\
(\mathrm{n}=50)\end{array}$} & & \multicolumn{2}{c}{$\begin{array}{c}\text { Group II } \\
(\mathrm{n}=50)\end{array}$} & $\mathrm{p}$ value \\
\cline { 2 - 3 } & Number & $\%$ & & Number & $\%$ & \\
\hline Service & 24 & 48.0 & & 31 & 62.0 & \\
Business & 19 & 38.0 & & 14 & 28.0 & 0.29 \\
Farmer & 1 & 2.0 & & 3 & 6.0 & \\
Housewife & 5 & 10.0 & & 2 & 4.0 & \\
Others & 1 & 2.0 & & 0 & 0 & \\
\hline
\end{tabular}

Chi-square test was employed to analyse the data

Table-III

Distribution of the study patients according to risk factors $(n=100)$ ।

\begin{tabular}{lccccccc}
\hline Risk Factors & \multicolumn{2}{c}{$\begin{array}{c}\text { Group I } \\
(\mathrm{n}=50)\end{array}$} & & \multicolumn{2}{c}{$\begin{array}{c}\text { Group II } \\
(\mathrm{n}=50)\end{array}$} & $\mathrm{p}$ value \\
\cline { 2 - 3 } & \multicolumn{2}{c}{ Number } & $\%$ & & Number & $\%$ & \\
\hline Smoking habit & 28 & 56.0 & & 39 & 78.0 & $0.02^{\mathrm{s}}$ \\
Hypertension & 23 & 46.0 & & 28 & 56.0 & $0.31^{\mathrm{ns}}$ \\
Diabetes mellitus & 15 & 30.0 & & 31 & 62.0 & $0.001^{\mathrm{s}}$ \\
Dyslipidemia & 2 & 4.0 & & 19 & 38.0 & $0.001^{\mathrm{s}}$ \\
Family H/O CAD & 20 & 40.0 & & 16 & 32.0 & $0.41^{\mathrm{ns}}$ \\
\hline
\end{tabular}

$\mathrm{s}=$ Significant, $\mathrm{ns}=$ Not significant, Data were analysed using Pearson Chi-Square Test.

Table III compares the risk factors between the two groups which showed that the incidence of smoking, Diabetes mellitus and Dyslipidemia was statistically insignificant $(\mathrm{p}>0.05)$ in group II.

\section{Table-IV}

Distribution of the study patients according to site of $M I(n=100)$

\begin{tabular}{lccccccc}
\hline Site of MI & \multicolumn{2}{c}{$\begin{array}{c}\text { Group I } \\
(\mathrm{n}=50)\end{array}$} & & \multicolumn{2}{c}{$\begin{array}{c}\text { Group II } \\
(\mathrm{n}=50)\end{array}$} & $\mathrm{p}$ value \\
\cline { 2 - 3 } & Number & $\%$ & & Number & $\%$ & \\
\hline Anterior & 18 & 36.0 & & 28 & 56.0 & $0.04^{\mathrm{s}}$ \\
Inferior & 31 & 62.0 & & 19 & 38.0 & $0.02^{\mathrm{s}}$ \\
Lateral & 1 & 2.0 & & 3 & 6.0 & $0.31^{\mathrm{ns}}$ \\
\hline
\end{tabular}

$\mathrm{s}=$ Significant, $\mathrm{ns}=$ Not significant, Data were analysed using Pearson Chi-Square Test.

Table IV shows site of MI in study patients and found that $18(36 \%)$ patients in group I and 28 (56\%) patients in group II had anterior MI. 31 (62\%) patients in group I and 19 (38\%) patients in group II had inferior MI. Both site of MI were found statistically significant $(\mathrm{p}<0.05)$. Lateral
MI was found 1 (2\%) patients in group I and 3 $(6 \%)$ in group II. No statistically significant difference was found in lateral MI.

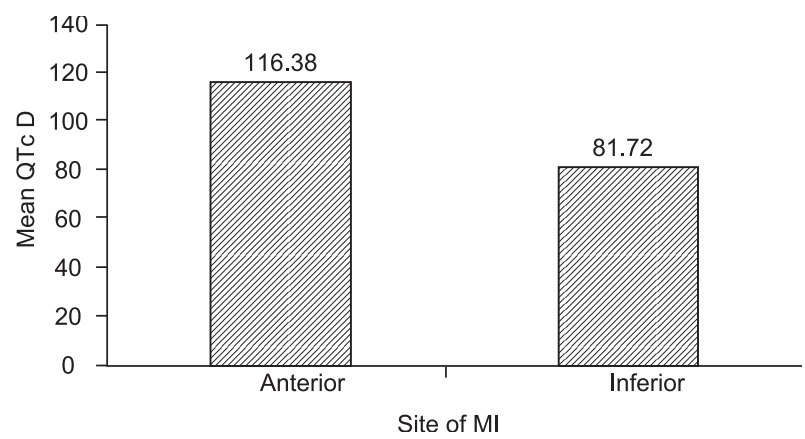

Fig.-2: Comparison of QTc Dispersion between anterior and inferior $M I$.

Figure 2 shows the mean QTc dispersion was much higher in anterior MI (116.38) than that in inferior MI (81.72).

\section{Table-V}

Distribution of the study patients according to vessel score $(n=100)$

\begin{tabular}{lcccccc}
\hline Vessel Score & \multicolumn{2}{c}{$\begin{array}{c}\text { Group I } \\
(\mathrm{n}=50)\end{array}$} & & \multicolumn{2}{c}{$\begin{array}{c}\text { Group II } \\
(\mathrm{n}=50)\end{array}$} & $\mathrm{p}$ value \\
\cline { 2 - 3 } & Number & $\%$ & & Number & $\%$ & \\
\hline Score -0 & 8 & 16.0 & & 0 & 0.0 & \\
Score -1 & 26 & 52.0 & & 5 & 10.0 & \\
Score -2 & 16 & 32.0 & & 25 & 50.0 & \\
Score -3 & 0 & 0.0 & & 20 & 40.0 & \\
\hline
\end{tabular}

Mean \pm SDRange $(\min -\max ) 1.16 \pm 0.68(0-2) 2.30 \pm 0.64(1-3)$ $0.001^{\mathrm{s}}$

$\mathrm{s}=$ Significant, $\mathrm{P}$ value reached from unpaired $\mathrm{t}$ test.

The table $\mathrm{V}$ shows the vessel score of the study patients. The mean vessel score for group I patients was $1.16 \pm 0.68$ and that of group II patients was $2.30 \pm 0.64$ and the mean difference was statistically significant $(\mathrm{p}<0.05)$ in unpaired t-test.

\section{Table VI}

Association between QTc dispersion and number of vessels involved $(n=100)$

\begin{tabular}{lccc}
\hline $\begin{array}{l}\text { No. of vessel } \\
\text { involved }\end{array}$ & \multicolumn{2}{c}{ QTc dispersion } & P value \\
\cline { 2 - 3 } & Mean & SD & \\
\hline Single & 57.05 & 28.45 & $0.001^{\mathrm{s}}$ \\
Double & 102.00 & 46.95 & \\
Triple & 177.60 & 28.92 & \\
\hline
\end{tabular}

$\mathrm{s}=$ Significant, $\mathrm{P}$ value reached from ANOVA test. 
The table VI shows that higher the number of vessels involved, the greater is the QTc dispersion with mean score in single, double and triple vessel disease being 57.05, 102.00 and 177.60 respectively $(\mathrm{p}<0.05)$.

\section{Table VII}

Distribution of the study patients according to Friesinger score $(n=100)$

\begin{tabular}{|c|c|c|c|c|c|}
\hline \multirow[t]{2}{*}{$\begin{array}{l}\text { Friesinger } \\
\text { Score }\end{array}$} & \multicolumn{2}{|c|}{$\begin{array}{l}\text { Group I } \\
(\mathrm{n}=50)\end{array}$} & \multicolumn{2}{|c|}{$\begin{array}{l}\text { Group II } \\
(\mathrm{n}=50)\end{array}$} & \multirow[t]{2}{*}{$\mathrm{p}$ value } \\
\hline & Number & $\%$ & Number & $\%$ & \\
\hline 0 & 5 & 10.0 & 0 & 0.0 & \\
\hline $1-4$ & 24 & 48.0 & 3 & 6.0 & \\
\hline $5-10$ & 21 & 42.0 & 27 & 54.0 & \\
\hline $11-16$ & 0 & 0.0 & 20 & 40.0 & \\
\hline $\begin{array}{l}\text { Mean } \pm \mathrm{SD} \\
\text { Range } \\
(\min -\max )\end{array}$ & \multicolumn{2}{|c|}{$\begin{array}{c}4.84 \pm 2.56 \\
(0-9)\end{array}$} & \multicolumn{2}{|c|}{$\begin{array}{c}9.80 \pm 2.60 \\
(4-16)\end{array}$} & $0.001^{\mathrm{s}}$ \\
\hline
\end{tabular}

$\mathrm{s}=$ Significant, $\mathrm{P}$ value reached from unpaired $\mathrm{t}$ test.

Table VII shows Friesinger index of the study patients. Friesinger socre 0 was $5(10 \%)$ patients in group I and no patients in group II. Friesinger score 1-4 was $24(48 \%)$ and3 (6\%) in group I and II respectively. Friesinger score 5-10 was found 21 (42\%) patients in group I and 27 (54\%) patients in group II. Friesinger score 11-16 was found no patients in group I and 20 (40\%) patients in group II. The mean difference was statistically significant $(p<0.05)$ in unpaired t-test.

\section{Table VIII}

Distribution of the study patients according to significant coronary artery disease defined by Friesinger index $(n=100)$

\begin{tabular}{lccccc}
\hline $\begin{array}{l}\text { QTc } \\
\text { dispersion }\end{array}$ & $\begin{array}{c}\text { Insignificant } \\
\text { (Friesinger } \\
\text { score } \\
0-4 \text { ) CAD }\end{array}$ & $\begin{array}{c}\text { Significant } \\
\text { (Friesinger } \\
\text { score }\end{array}$ & P value \\
& Number & $\%$ & Number & $\%$ & \\
\hline $\begin{array}{l}\text { QTc }<60 \\
\text { milliseconds }\end{array}$ & 28 & 56.0 & 22 & 44.0 & $0.001^{\mathrm{s}}$ \\
$\begin{array}{l}\text { QTc } \geq 60 \\
\text { milliseconds }\end{array}$ & 3 & 6.0 & 47 & 94.0 & \\
\hline s=Significant, P value reached from Chi Square t test.
\end{tabular}

Table VIII shows patients with QTc $<60$ msec a total of 50 patients were observed out of which, 28 (56\%) had insignificant CAD and $22(44 \%)$ had significant CAD. On the other hand, patients with $\mathrm{QTc} \geq 60$ msec 50 patients were observed that of, $3(6 \%)$ had insignificant $\mathrm{CAD}$ and 47 (94\%) had significant CAD. The difference was statistically significant $(p<0.05)$, significant CAD was significantly higher in patients with QTc dispersion $\geq 60$ miliseconds.

Table-IX

Multivariate predictors of significant coronary artery disease (Friesinger score $\geq 5$ ) with risk factors $(n=100)$

\begin{tabular}{lcccc}
\hline Parameters & & \multicolumn{2}{r}{ P value } \\
& OR & Lower & Upper & \\
\hline Age (>50 years) & 2.33 & 1.014 & 5.371 & $0.04^{\mathrm{s}}$ \\
Sex (Male) & 2.54 & 0.536 & 12.058 & $0.22^{\mathrm{ns}}$ \\
Smoking & 2.68 & 1.130 & 6.375 & $0.02^{\mathrm{s}}$ \\
Diabetes Mellitus & 2.42 & 1.032 & 5.647 & $0.04^{\mathrm{s}}$ \\
Dyslipidemia & 1.86 & 1.512 & 2.281 & 0.01 \\
Family history & 1.06 & 0.455 & 2.478 & $0.89^{\mathrm{ns}}$ \\
of CAD & & & & \\
Thrombolysis & 0.23 & 0.027 & 1.972 & $0.14^{\mathrm{ns}}$ \\
LVEF (<50\%) & 1.67 & 0.698 & 3.941 & $0.25^{\mathrm{ns}}$ \\
QTcD & 1.05 & 1.027 & 1.071 & $0.001^{\mathrm{s}}$ \\
\hline
\end{tabular}

$\mathrm{s}=$ Significant. $\mathrm{ns}=$ Not significant

Table IX shows Age, smoking, diabetes mellitus and QTcD were associated significantly for significant coronary artery disease in multivariate analysis.

\section{Prolonged QTe dispersion and vessel score:}

This study shows that there is a positive correlation between prolonged QTc dispersion and coronary artery disease severity in terms of vessel score $(\mathrm{r}=0.75, \mathrm{p}<0.001)$

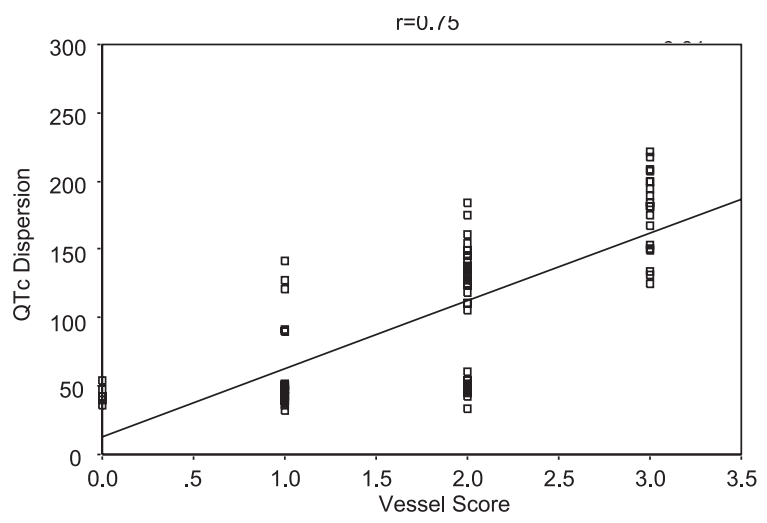

Fig-3: Correlation prolonged QTc dispersion between and vessel score 
Prolonged QT dispersion and Friesinger score:

This study shows that there is a positive correlation between prolonged QTc dispersion and coronary artery disease severity in terms of Friesinger score $(r=0.79, p<0.001)$

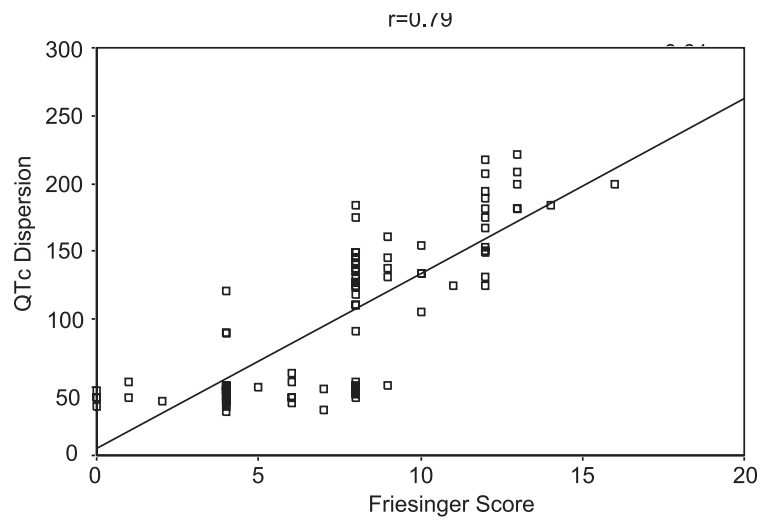

Fig-4.: Correlation between prolonged QTC dispersion and Friesinger score

\section{Prolonged QTc dispersion and Leaman}

score :

This study shows that there is a positive correlation between prolonged QTc dispersion and coronary artery disease severity in terms of Leaman score $(r=0.71, p<0.001)$.

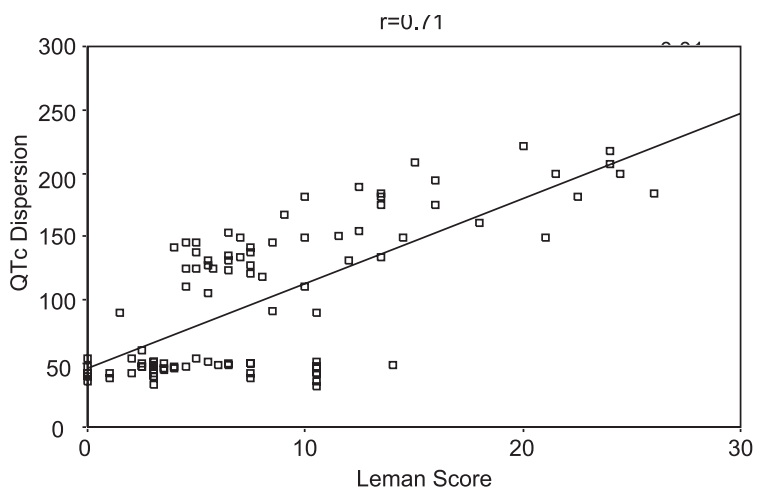

Fig-5: Correlation between prolonged QTC dispersion and Leaman score

\section{Discussion:}

The mean age of the patients was $49.3 \pm 9.9$ years and $52.2 \pm 9.5$ years in group I and group II respectively, which was almost similar between two groups. Maximum frequency was found in the age group of 51-60 years. Almost similar mean age was observed by Tikiz,et al. and
Yilmaz,et al. which are comparable with the current study. ${ }^{15,17}$ Uddin $^{21}$ found mean age of $49.7 \pm 11.3$ in over all patients of IHD. These small variations of mean age among different study may be due to differences in study design. Hailer et al. found significant difference in mean age between two groups. ${ }^{22}$ There was no statistically significant difference in mean age two between QTc dispersion groups in our study. In this study it was observed that in patients with QTc dispersion<60 millisecond in group I, 45 (90\%) patients were male and $5(10 \%)$ patients were female. With QTc dispersion.>60millisecond in group II, 48 (96\%) patients were male and 2 (5\%) were female. Male female ratio was 13.28:1.Sex distribution of the patients in two CAD severity groups revealed significant impact of male sex in severity of CAD. No significant $(\mathrm{p}>0.05)$ was found between two groups regarding sex distribution. Hegazy et al. also show no significant difference regarding sex distribution between two groups. ${ }^{23}$ Sex distribution of the patients in two groups revealed significant impact of male sex in severity of CAD $(\mathrm{P}=0.025)$. Similar male preponderance was found in almost all studies in IHD. Male female ratio was 5.9:1, 4.6:1 and 4.95:1 in respectively Khan, Uddin. ${ }^{21,24}$ Similarly, Bampi, et al., Luz, et al. and Candil, et al. found that CAD was more common in male subject. ${ }^{25-27}$ Female are less prone to developed IHD in premenopausal age due to protective role of estrogen, moreover smoking as a risk factor of IHD is less common in our country among female, which may explain male predominance of IHD. ${ }^{28}$ The common risk factors for coronary artery disease in the present study showed that, smoking was the highest in Group-I followed by hypertension, family history of $\mathrm{CAD}$, diabetes mellitus (DM) and dyslipidemia. In Group-II smoking was also the commonest followed by diabetes mellitus, hypertension, dyslipidemia and family history of CAD. There was statistically significant of difference between the two groups in terms of smoking, diabetes mellitus and dyslipidemia. Smoking habit was found 28 (56\%) in group I and 39 (78\%) patients in group II and statistically significant $(p<0.05)$.In group I, 23 $(46 \%)$ patients were hypertensive and in group II, $28(56 \%)$ patients were hypertensive and statistically insignificant $(p>0.05)$. Diabetes 
mellitus was found $15(30 \%)$ and $31(62 \%)$ patients with statistically significant $(\mathrm{p}<0.05)$ in group I and group II respectively. Dyslipidemia was found $2(4 \%)$ and $19(38 \%)$ patients with statistically significant $(\mathrm{p}<0.05)$ in group I and group II respectively. Family history of CAD was found $20(40 \%)$ and $16(32 \%)$ patients with statistically insignificant ( $>00.05)$ in group I and group II respectively. Khan and Uddin found smoking as a highest prevalent risk factor. ${ }^{21}$, ${ }^{24}$ This finding of the risk factors was similar regarding smoking habit \& dyslipidemia with the study conducted by Tikiz et al. ${ }^{21}$ In this study it was observed that $36 \%$ patients in group I and $56 \%$ patients in group II had anterior MI. Inferior MI was found $62 \%$ in group I and $38 \%$ in group II. Both site of MI were found statistically significant $(\mathrm{p}<0.05)$ in group II . Lateral MI was found $2 \%$ in group I and $6 \%$ in group II. No statistically significant difference was found in lateral MI. It has been reported that QT and QTc dispersions are dependent on the infarct size, and the greater values of QT and QTc dispersions associated with anterior MI can be explained by larger infarction. ${ }^{29,}{ }^{30} \mathrm{At}$ home Rahman found anterior MI in $51.2 \%$ cases and inferior MI in $45 \%$ cases. ${ }^{31}$ Haque found that anterior MI was highest in their study population followed by inferior MI. ${ }^{32}$ Coronary angiogram was performed in all study population during index hospital admission. The findings were analyzed as a number of vessel involvements, i.e vessel score, also by friesinger coronary angiographic severity index and Leaman scoring system. Possible scores of vessel score ranges from zero to three vessel disease ${ }^{33}$ In this study it was observed that the mean vessel score for group I patients was $1.16 \pm 0.68$ and that of group II patients was $2.30 \pm 0.64$ and the mean difference was statistically significant $(p<0.05)$. The mean vessels score was significantly $(p<0.001)$ higher in group II in comparison with group I, indicating more severe coronary artery disease in group II patients. It was found that among group I patients, highest percentage had one vessel score $52 \%$ followed by two vessel score $32 \%$, three vessel score $0 \%$ and 0 score $16 \%$. In group II patients, highest percentage had two vessel score $50 \%$ followed by three vessel score $40 \%$, one vessel score $10 \%$ and no patient had 0 score. There was an association between QTc dispersion and number of vessel involvement. Patients those had single vessel involvement had mean QTc dispersion57.05, patients those had double vessel disease mean QTc dispersion was 102.00 and patients those had triple vessel involvement had mean QTc dispersion 177.60. There was a strong positive correlation with the QTc dispersion and increasing number of vessel involvement (Pearson's correlation coefficient). The score in Fresinger index ranges from 0 to $15 .^{34}$ In this study Friesinger score 1-4 was found $48 \%$ and $6 \%$ patients in group I and II respectively. Friesinger score 5-10 was found $42 \%$ patients in group I and 54\% patients in group II. Friesinger score 11-15 was found no patients in group I and $40 \%$ patients in group II respectively. The mean Friesinger score for group I patients was $4.84 \pm 2.56$ and that of group II patients was $9.80 \pm 2.60$. The mean difference was significantly $(p<0.05)$ higher in group II patients. There was a strong positive correlation between the QT dispersion and Friesinger coronary angiographic severity score (Pearson's correlation coefficient). Luz et al. found Friesinger index 0 in $19.0 \%$ patients, 1 - 4 in $17.9 \%$ patients, $5-10$ in $36.1 \%$ patients and $11-15$ in $27.0 \%$ patients. ${ }^{26}$ There was a strong positive correlation between the QTc dispersion and Leaman score (Pearson's correlation coefficient). Bampi et al observed that, Friesinger score 0-4 indicates less extensive disease and Friesinger score e"5 indicates extensive coronary atherosclerosis with extensive coronary artery disease. ${ }^{25}$ In group I patients $56 \%$ had insignificant coronary artery disease and $44 \%$ had significant coronary artery disease defined by Friesinger index $(n=100)$. In group II patients $6 \%$ had insignificant coronary artery disease \& had $94 \%$ significant coronary artery disease. It indicates that the difference was statistically significant $(\mathrm{p}<0.05), \mathrm{CAD}$ was significantly higher in patients with QTc dispersion $\geq 60$ milliseconds. Multivariate logistic regression analysis and odds ratio (95\% CI) of explanatory variables was done for $100 \mathrm{ST}$ elevation myocardial infarction patients considering Friesinger score as dependant variable. According to multivariate predictors of Friesinger score it was observed that Age, 
smoking, diabetes mellitus and dyslipidemia were more likely to develop significant coronary artery disease (Friesinger score e"5). Most important finding of the present study is that prolonged QTc dispersion is a powerful independent and incremental predictor of severity of coronary artery disease in patients presented with acute ST segment elevation myocardial infarction.

\section{Stydy Limitation:}

Although the result of this study support the hypothesis, there are some fact which might affect the result-Number of study population limited, It was a single centre study, QTc dispersion measurements were done manually by a single observer, Angiography was evaluated by visual estimation, so there was chance of inter observer and intra observer variation of interpretation of the severity of the CAD.

\section{Conclusion:}

QTc dispersion has emerged as a noninvasive measurement for quantifying the degree of myocardial repolarization inhomogencity. QTc dispersion $>60 \mathrm{~ms}$ had independent predictive value for the severity of coronary artery disease. The greater the QTc dispersion the higher the number of coronary artery involvement. We observed that there is a positive correlation between prolonged QT dispersion and coronary artery disease severity in terms of Vessel score, Friesinger score, Leaman score.

\section{Recommendation:}

We recommend that QTc dispersion $>60$ miliseconds on admission ECG, should raise the suspicion of coronary artery involvement in patient of acute myocardial infarction and these patients should be give special attention, referral $\&$ early intervention. In future large number of sample \&multicentre study need to establish the recommendation.

Conflict of Interest - None.

\section{References:}

1. Chaturvedi V, Bhargava B. Health Care delivery for coronary heart disease in India-where are we headed? Am Heart Hospital $j$ 2007; 5: 32-37.
2. Murray CJL, Lopez AD. Global health statistics Global burden of disease and injury series. Boston, Mass: Harvard school of public health 1996; 34 : 702-703.

3. Reddy KS, Yousuf S. Emerging epidemic of cardiovascular disease in developing countries. Circulation 1998; 97: 596-601.

4. Yousuf S, Reddy S, Ounpuu S, and Anard S. Global burden of disease, Part I: general considerations, the epidemiologic transition, risk factors and impact of urbanization. Circulation 2001; 104: 2746-2753.

5. Reddy KS. Cardiovascular diseases in non western countries. N Eng J Med 2004; 350: 2438-2440.

6. Ali M. Coronary heart diseases: Need for epidemiological studies and Guidelines for South Asians, (editorial). Bangladesh Heart J 2006; 21:1.

7. Yousuf S, Ounpuu S. Tracing the growing epidemic of cardiovascular disease in South Asia. J Am Coll Cardio 2001; 38: 688-689.

8. Islam MN, Ali MA \& Ali M. Spectrum of Cardiovascular Disease: The current scenario in Bangladesh. Bangladesh Heart Journal 2004; 19: 1-7.

9. Khandaker RK, Hosssain D, Hossain M \& Shamsuzzaman. Retrospective analysis of acute myocardial infarction: A 4 years study of 2690 patients. Bangladesh Heart J 1987; 1: 14-17.

10. Zaman MM, Jasimuddin A, Chowdhury SR. Prevalence of Ischaemic Heart Disease in a Rural Population of Bangladesh. Indian Heart Journal 2007; 59(3): 316-322.

11. Murkofsky RL, Mehta D, Dangas G. A prolonged QRS duration on surface ECG is a specific indicator of left ventricular dysfunction. J Am Coll Cardio 1998; 32: 476-482.

12. P Igor, Tatjana S and Peeter L. Prognostic value of QT interval dispersion during exercise in patients with stable angina. Seminars in Cardiovascular Medicine 2008; 14(3):11-15.

13. Roukema G, Singh JP, Meijs M. Effect of exercise-induced ischemia on QT interval dispersion. Am Heart J 1998;135: 88-92.

14. Kramer B, Brill M, Bruhn A, Kubler W. Relation between the degree of coronary artery disease and left ventricular function and the duration of the QT-interval in ECG. Eur Heart J 1986; 7: 14-24.

15. Týkýz H, Terzi T, Balbay Y. QT dispersion in single coronary artery disease: is there a relation between QT dispersion and diseased coronary artery or lesion localization?. Angiology 2001; 52: 43-51.

16. Stierle U, Giannitsis E, Sheikhjdeh A. Relation between QT dispersion and the extent of myocardial ischemia in patients with three vessel coronary artery disease. Am $J$ Cardiol 1998; 81: 564-568.

17. Yýlmaz R, Demirbad R, Gur M. The association of QT dispersion andQT dispersion ratio with extent and severity of coronary artery disease. Ann Noninv Electrocardiol 2006; 11: 43-51.

18. Yunus A, Gillis AM, Traboulsi M, et al. Effect of coronary angioplasty on precordial QT dispersion. Am J Cardiol. 1997; 79(10): 1339-1342. 
19. Polychronis Â. Effects of ischemia on QT dispersion during spontaneous anginal episodes. Journal of Electrocardiology 1999; 32(3): 199-206.

20. Chugh S N. Text book of clinical electrocardiography, $2^{\text {nd }}$ edition. New Delhi: Jaypee brothers medical publishers $(\mathrm{P})$ ltd. 2006.

21. Uddin M. Association of central pulse pressure with the extent of angiographically detected coronary artery disease, MD (cardiology), Thesis, Dhaka University . 2011.

22. Hailer, Birgit, Leeuwen, And Peter. Coronary artery disease may alter the spatial dispersion of the QT interval at rest. Annals of noninvasive electrocard 1999; 4(3):267273.

23. Hegazy AM, Kade BAA. QT Dispersion Immediately after Exercise Test Improves Sensitivity and Specificity for Diagnosis of Ischemic Heart Disease. Kuwait Medical Journal 2005; 37(3): 176-181.

24. Khan MMR. Extent of ST segment depression predicts inhospital outcome in non-ST segment elevation acute coronary syndrome, Thesis, NICVD. 2008.

25. Bampi ABA, Rochitte CE, Favarato D, Lemos PA and Luz PL. Comparison of non-invasive methods for the detection of coronary atherosclerosis. Clinics 2009; 64: 675-682.

26. Luz PL, Favarato D, Faria NJR, Chagas LM. High ratio of triglycerides to HDL-cholesterol ratio predicts extensive coronary disease. Clinics 2008; 64: 427-432.

27. Candil JJ, Gonzalez IC, Martin F, Paban P. Relationship between QRS duration \& prognosis in non-ST-segment elevation acute coronary syndrome. Int J Cardiol 2008; 126:196-203.
28. Bueno H, Lo'pez-Palop R, Perez-David E. Combined effect of age on acute inferior myocardial infarction prognosis. Circulation 1998: 98:1714-1720.

29. Moreno FL, Villanueva T, Karagounis LA, Anderson JL. Reduction in QT interval dispersion by successful thrombolytic therapy in acute myocardial infarction. TEAM-2 Study Investigators. Circulation 1994; 90: 94-100.

30. Puljevic D, Smalcelj A, Durakovic Z, Goldner V. Effects of postmyocardial infarction scar size, cardiac function, and severity of coronary artery diseaseon QT interval dispersion as a risk factor for complex ventricular arrhythmia. Pacing. Clin Electrophysiol, 1998; 21:15081516.

31. Rahman MM. Coronary artery profile in patients with myocardial infarction after streptokinase therapy, MD(Cardiology),Thesis, University of Dhaka. 1998.

32. Hoque S. Status of cardiovascular service in Bangladesh. Heart Res Inst Bull 1993; 8: 21-24.

33. Sullivan DR, Thomas H, Marwick S, Ben FD. A new method of scoring coronary angiograms to reflect extent of coronary atherosclerosis and improve correlation with major risk factors. Am Heart $J$ 1990; 119(6): 1262-1267.

34. Ringqvist I, Fisher LD, Mock M, Devis KB. Prognostic value of Angiographic Indices of coronary artery disease from the Coronary Artery Surgery Study (CASS). J Clin Invest 1983; 71: 1854-1866.

35. Paventi S, Bevilacqua U, Parafati MA, Di Luzio E. QT dispersion and early arrhythmic risk during acute myocardial infarction. Angiology 1999;50: 209-215. 